\title{
Comparison of clinical outcomes between mesh-reinforced pancreatojejunostomy and pancreatogastrostomy following pancreaticoduodenectomy: a cohort study
}

Junhai Pan $^{\dagger}$, Xiaolong Ge ${ }^{\dagger}$, Wei Zhou*, Xin Zhong, Lihu Gu, Hepan Zhu, Xinlong Li, Weilin Qi and Xianfa Wang ${ }^{*}$ (D)

\begin{abstract}
Background: Postoperative complications, especially postoperative pancreatic fistulas, remain the major concern following pancreaticoduodenectomy (PD). Mesh-reinforced pancreatic anastomoses, including pancreatojejunostomy $(\mathrm{PJ})$ and pancreatogastrostomy (PG), are a new effective technique in PD. This study was conducted to analyze the safety and efficacy of this new technique and to compare the results of mesh-reinforced PJ vs PG.

Methods: A total of 110 patients who underwent PD between August 2005 and January 2016 were eligible in this study. Perioperative and postoperative data of patients with a mesh-reinforced technique were analyzed. Data were also grouped according to the procedure performed: mesh-reinforced PJ and mesh-reinforced PG.

Results: Among patients undergoing PD with the mesh-reinforced technique, 42 had postoperative complications, and the comprehensive complication index (CCI) was $32.7 \pm 2.5$. Only $10 \%$ of patients had pancreatic fistula; three were grade $A$, six were grade $B$, and two were grade $C$. Biliary fistula occurred in only $8.2 \%$ of patients. Patients undergoing mesh-reinforced PG showed a significantly lower rate of CCl than did mesh-reinforced PJ patients (27.0 \pm 2.1 vs $37.0 \pm 3.9$, $p<0.05$ ). The mesh-reinforced PG was also favored over mesh-reinforced PJ because of significant differences in intraabdominal fluid collection (5.9\% vs 18.6\%, $p<0.05$ ) and delayed gastric emptying (3.9\% vs $15.3 \%, p<0.05)$.

Conclusions: PD with the mesh-reinforced technique was a safe and effective method of decreasing postoperative pancreatic fistula. Compared with mesh-reinforced PJ, mesh-reinforced PG did not show significant differences in the rates of pancreatic fistula or biliary fistula. However, $\mathrm{CCl}$, intra-abdominal fluid collection, and delayed gastric emptying were significantly reduced in patients with mesh-reinforced PG.
\end{abstract}

Keywords: Pancreatogastrostomy, Pancreatojejunostomy, Pancreaticoduodenectomy, Mesh, Pancreatic fistula

\section{Background}

Pancreaticoduodenectomy (PD) is considered to be one of the most difficult and complex surgery since Whipple and colleagues published the first report of patients undergoing PD in 1935 [1]. In addition, PD has been regarded to be a standard surgical procedure in pancreatic cancer and other lesions which are located in periampullary region, while it is always with high postoperative complications

\footnotetext{
* Correspondence: zhouw@srrsh.com; 3195011@zju.edu.cn

†Junhai Pan and Xiaolong Ge contributed equally to this work. Department of General Surgery, School of Medicine, Sir Run Run Shaw Hospital, Zhejiang University, 3 East Qingchun Road, Hangzhou 310016, Zhejiang, China
}

rates [2-5]. Generally, postoperative pancreatic fistula (POPF), biliary fistula, intra-abdominal fluid collection, intra-abdominal hemorrhage, and delayed gastric emptying are common post-pancreaticoduodenectomy complications even there are advances in surgical techniques in recent years, and it leads to prolonged hospital stays and increased medical costs $[6,7]$. Among all the postoperative complications, POPF is regarded as Achilles heel of PD. To prevent complications, various strategies have been tried including pharmacologic prophylactic approaches and surgical techniques $[8,9]$. These include octreotide, occluding the main duct with rubber or fibrin glue, pancreatic duct stenting, suture ligation of the

(c) The Author(s). 2018 Open Access This article is distributed under the terms of the Creative Commons Attribution 4.0 International License (http://creativecommons.org/licenses/by/4.0/), which permits unrestricted use, distribution, and 
pancreatic duct, pancreaticoenterostomy with the jejunum or stomach, modification of suturing techniques, and others [10-12]. Although the rate of mortality after PD has decreased to less than $5 \%$, the morbidity rate is still higher, ranging from 40 to $60 \%$ [13]. As the most harmful complications, the incidence of POPF has been reported, with highly variable rates depending on various definitions, ranging from 10 to 29\% [14]. Postoperative complications at or around the anastomosis following PD were the most frequent and dangerous, occurring almost 25 times with five deaths [15]. Therefore, improvements in perioperative management and surgical technique remain crucial to decrease complications following PD.

For almost 10 years, we have used the new mesh-reinforced technique described by Peng and his colleagues to minimize postoperative complications after PD [16-18]. This safe and simple technique is characterized by a strip of polypropylene mesh, and it is wrapped around the pancreatic stump. Wang et al. [17] reported that no leakage occurred in 10 patients undergoing mesh-reinforced pancreaticojejunostomy (PJ) in PD. Only one patient developed grade A pancreatic leakage after mesh-reinforced pancreaticogastrostomy (PG) in a series of 13 initial cases $[14,18]$. However, a large sample analysis is needed to evaluate whether the mesh-reinforced technique is safe and effective following PD. Some studies suggested that PG reduced biliary fistula and delayed gastric emptying and postoperative collections in patients following PD more so than did PJ $[19,20]$. Therefore, whether mesh-reinforced PG is better than mesh-reinforced PJ in postoperative complications following PD remains unknown.

In this study, we evaluated the outcomes of the meshreinforced technique in 110 patients undergoing PD. Either PG or PJ was performed depending on the surgeon's preference. Postoperative complications were assessed for both types of reconstruction.

\section{Methods \\ Study patients}

Consecutive patients undergoing pancreatoduodenectomy because of malignant or non-malignant disease were included and analyzed in a tertiary referral hospital between August 2005 and January 2016. Written informed consent which was associated with the potential surgical risks was signed by all the patients. The present research was approved by the ethics committee of our hospital.

\section{Surgical techniques}

In our institution, we used the mesh-reinforced technique of pancreaticogastrostomy described by Professor Peng [16]. During the entire surgical procedure, non-absorbable (polypropylene mesh, large pore, Ethicon, New Jersey, USA) or absorbable (Cook, Limerick, Ireland) hernia grafts were used to reconstruct the pancreatic remnant. Pancreatojejunostomy and pancreatogastrostomy were the techniques used in reconstruction of pancreatic anastomosis. The mesh-reinforced technique in pancreaticogastrostomy was designed such that the pancreatic remnant wrapped in a mesh strip was embedded into the stomach and was bound to its posterior wall by a single layer of continuous sutures [18]. The mesh-reinforced technique in pancreaticojejunostomy was designed such that the sheath of the jejunum was bound to the pancreatic remnant which was wrapped by a strip of mesh. In our institution, this mesh-reinforced technique was the first choice for reconstruction following PD; it has been shown to be safe and effective for PG or PJ as described previously by Wang and Zhu $[17,18]$.

\section{Data collection}

The data collection was performed retrospectively including baseline characteristics and laboratory data from the database in our hospital. In addition, baseline characteristics mainly included gender, age, body mass index (BMI), comorbidities, pancreatic gland texture, mesh materials, American Society of Anesthesiologists (ASA), and the surgical indication. Other data about surgery included operative time, intraoperative blood transfusion, intraoperative bleeding, and the size of pancreatic duct.

\section{Definition of outcomes}

The primary outcome was pancreatic fistula after surgery according to the definition by International Study Group of Pancreatic Fistula (ISGPF). A clinical grading system of POPF was proposed as grades $\mathrm{A}, \mathrm{B}$, and $\mathrm{C}$ [14]. The comprehensive complication index (CCI) was created to evaluate postoperative complications, and the CCI was a score calculated based on the Clavien-Dindo system [21, 22]. Mild complications included grades I and II according to the Clavien-Dindo system, and the major complications included grades III to IV. Furthermore, the CCI system was reported to be more sensitive than the existing morbidity endpoints [21, 23]. The website of http://www.assessurgery.com was used to calculate the CCI in each patient [24]. Other outcomes included postoperative stay, biliary fistula, abdominal bleeding, intra-abdominal fluid collection, delayed gastric emptying, and reoperations [25].

\section{Statistical analysis}

SPSS version 23.0 software was used in analyzing all the data. Continuous data were presented as mean \pm SD, and categorical data were presented as number (\%). The continuous variables were analyzed by Mann-Whitney $U$ test or Student's $t$ test, and Pearson's chi-square test or the Fisher exact test was used to analyze categorical 
variables. The statistically significance was defined as $P$ value $<0.05$.

\section{Results}

\section{Patients}

In total, 110 patients underwent pancreatic resections by the mesh-reinforced technique and were included in this retrospective observational analysis, of which $84.5 \%$ were confirmed to be soft parenchyma. Among 110 patients following PD, 25.5\% had a dilated pancreatic duct with the diameter larger than $4 \mathrm{~mm}$. Fifty-one patients underwent PG, and 59 patients underwent PJ with the new mesh-reinforced technique. In the PG group, there were 27 males and 24 females, and their mean age was 60.9 years. In the PJ group, the patients' mean age was 57.1 years, and 38 patients were male. No statistically significant differences was found in the distributions of comorbidities, ASA, pancreatic gland texture, pancreatic duct size, age, and gender between the PG group and PJ group (Table 1). A total of 35 patients underwent PD due to ampullary carcinoma, 16 patients had duodenal cancer, 16 patients had distal biliary cancer, and 15 patients were diagnosed with ductal cancer. The remaining 28 patients had other conditions, primarily cystic tumors (9 patients), endocrine tumors (5 patients), and intraductal papillary mucinous tumors ( 5 patients). There was no significant difference between the PG group and the PJ group in terms of surgical indications (Table 2).

\section{Postoperative outcomes}

After PD with the mesh-reinforced technique, 68 patients recovered uneventfully, and 42 patients suffered postoperative complications. Some patients were found to have more than two complications after surgery. According to the Clavien-Dindo system, there were $7 \mathrm{pa}$ tients (6.4\%) with mild complications (Clavien-Dindo grade I to II) and 35 patients (31.8\%) with major complications (Clavien-Dindo grade III to IV). The mean CCI based on Clavien-Dindo classification was $32.7 \pm 2.5$. The mean operative time was $368.0 \pm 8.2 \mathrm{~min}$, with estimated blood loss of $502.4 \pm 48.3 \mathrm{~mL}$. The mean anastomosis time of PD with this mesh-reinforced technique was $27.4 \pm 0.4 \mathrm{~min}$. A total of $37.3 \%$ of all the patients received intraoperative blood transfusions, and the length of the postoperative stay was $23.2 \pm 0.9$ days.

\section{Postoperative pancreatic fistula}

Various improvements in surgical technique were developed to avoid postoperative pancreatic fistula in studies regarding PD [13]. In our study, with the new mesh-reinforced technique, the rate of pancreatic fistula decreased to $10 \%$ in all the patients. According to the ISGPF definition [14], only three patients (2.7\%) had grade A pancreatic fistula, six patients (5.5\%) had grade $\mathrm{B}$, and two patients (1.8\%) had grade $\mathrm{C}$ (Table 3 ). In addition, only nine patients (8.2\%) suffered biliary fistula, and eight patients (7.3\%) had abdominal bleeding

Table 1 Baseline demographics in patients undergoing pancreatectomy

\begin{tabular}{|c|c|c|c|c|}
\hline Characteristic & All $(n=110)$ & PG group $(n=51)$ & PJ group $(n=59)$ & $P$ value \\
\hline $\mathrm{Age}^{*}$ & $58.9 \pm 1.0$ & $60.9 \pm 1.3$ & $57.1 \pm 1.5$ & 0.07 \\
\hline Men, $n(\%)$ & $65(59.1)$ & $27(52.9)$ & $38(64.4)$ & 0.22 \\
\hline $\mathrm{BMI}^{*}, \mathrm{~kg} / \mathrm{m}^{2}$ & $23.0 \pm 0.3$ & $22.6 \pm 0.6$ & $23.3 \pm 0.4$ & 0.28 \\
\hline \multicolumn{5}{|l|}{ Comorbidities, $n$ (\%) } \\
\hline Diabetes mellitus, $n(\%)$ & $22(20)$ & $9(17.6)$ & $13(22.0)$ & 0.57 \\
\hline Hypertension, $n(\%)$ & $27(24.5)$ & $13(25.5)$ & $14(23.7)$ & 0.83 \\
\hline Operation time* ${ }^{*}$ min & $368.0 \pm 8.2$ & $342.4 \pm 11.7$ & $390.0 \pm 10.8$ & $<0.01$ \\
\hline $\mathrm{ASA} \geq 3, n(\%)$ & $19(17.3)$ & $9(17.6)$ & $10(16.9)$ & 0.92 \\
\hline Intraoperative blood transfusion, $n$ (\%) & $41(37.3)$ & $14(27.5)$ & $27(45.8)$ & 0.048 \\
\hline Estimated blood loss*, mL & $502.4 \pm 48.3$ & $392.2 \pm 31.8$ & $597.6 \pm 84.2$ & 0.03 \\
\hline Pancreatic gland texture, $n(\%)$ & & & & 0.55 \\
\hline Soft, $n(\%)$ & $93(84.5)$ & $42(82.4)$ & $51(86.4)$ & - \\
\hline Hard, $n(\%)$ & $17(15.5)$ & $9(17.6)$ & $8(13.6)$ & - \\
\hline Mesh materials, $n(\%)$ & & & & $<0.01$ \\
\hline Non-absorbable, $n$ (\%) & $59(53.6)$ & $10(19.6)$ & $49(83.1)$ & - \\
\hline Absorbable, $n(\%)$ & $51(46.4)$ & $41(80.4)$ & $10(16.9)$ & - \\
\hline Pancreatic duct size (> 4 mm), $n$ (\%) & $28(25.5)$ & $14(27.5)$ & $14(23.7)$ & 0.66 \\
\hline The time of anastomosis*, min & $27.4 \pm 0.4$ & $29.1 \pm 0.7$ & $27.9 \pm 0.6$ & 0.21 \\
\hline
\end{tabular}

$P G$ pancreatogastrostomy, PJ pancreatojejunostomy

*Value are expressed as the mean \pm SE 
Table 2 Surgical indications in 110 pancreaticoduodenectomies

\begin{tabular}{lllll}
\hline & $\begin{array}{l}\text { All } \\
(n=110)\end{array}$ & $\begin{array}{l}\text { PG group } \\
(n=51)\end{array}$ & $\begin{array}{l}\text { PJ group } \\
(n=59)\end{array}$ & P value \\
\hline Ampullary carcinoma* & $35(31.8)$ & $17(33.3)$ & $18(30.5)$ & 0.75 \\
Distal biliary cancer* & $16(14.5)$ & $7(13.7)$ & $9(15.3)$ & 0.82 \\
Duodenal cancer* & $16(14.5)$ & $7(13.7)$ & $9(15.3)$ & 0.82 \\
Ductal cancer* & $15(13.6)$ & $7(13.7)$ & $8(13.6)$ & 0.98 \\
Cystic tumors* & $9(8.2)$ & $4(7.8)$ & $5(8.5)$ & 0.90 \\
Endocrine tumors* $^{*}$ & $5(4.5)$ & $3(5.9)$ & $2(3.4)$ & 0.53 \\
Intraductal papillary & $5(4.5)$ & $2(3.9)$ & $3(5.1)$ & 0.77 \\
mucinous tumor* & & & & \\
Other indications* & $9(8.2)$ & $4(7.8)$ & $5(8.5)$ & 0.90 \\
\hline
\end{tabular}

$P G$ pancreatogastrostomy, $P$ J pancreatojejunostomy

*Values are expressed as $n(\%)$

following PD. In addition, there were 14 patients (12.7\%) with intra-abdominal fluid collections, and 11 patients $(10.0 \%)$ had delayed gastric emptying. Finally, three patients $(2.7 \%)$ underwent the reoperation due to serious complications associated with the pancreatic fistula (Table 3).

\section{Comparison between PJ and PG with mesh-reinforced technique}

At present, PJ and PG are both widely used following $\mathrm{PD}$, and many studies have been published in order to compare the safety and efficacy of these two methods. Similarly, when the mesh-reinforced technique was performed during reconstruction in our study, the postoperative outcomes were compared between PJ and PG. The postoperative course showed that 18 (35.3\%) patients had complications in the PG group and that 24 (40.7\%) patients had complications in the PJ group. When compared to the PG group, there were statistically significant differences in the PJ group in terms of the comprehensive complication index $(27.0 \pm 2.1$ vs $37.0 \pm 3.9, P<0.05)$. In the PG group, three patients (5.9\%) had pancreatic fistulas, of which one patient (2.0\%) had grade A and two patients (3.9\%) had grade B. In the PJ group, eight patients (13.6\%) had pancreatic fistulas, of which two patients (3.4\%) were grade A, four patients $(6.8 \%)$ were grade B and two patients $(3.4 \%)$ were grade $\mathrm{C}$. The PJ group was more likely to have biliary fistula than was the PG group, even though no significant difference was found (11.9\% vs $3.9 \%)$. However, significant differences in favor of the PG group were investigated regarding intra-abdominal fluid collections (5.9\% vs $18.6 \%, P<0.05)$ and delayed gastric emptying (3.9\% vs $15.3 \%, P<0.05)$. The operative time was also significantly different between these two groups (PG, $342.4 \pm 11.7 \mathrm{~min}$ vs PJ, $390.0 \pm 10.8 \mathrm{~min}, P<0.01$ ), while the time of anastomosis was not significantly different between the PG and PJ groups. The PJ group also had significantly more estimated blood loss than the PG group. All the results are shown in Tables 1 and 3.

\section{Discussion}

In this study, the safety and efficacy of mesh-reinforced pancreatojejunostomy and pancreatogastrostomy in patients following pancreatoduodenectomy were compared. We found that patients undergoing pancreatoduodenectomy with the mesh-reinforced technique suffered fewer postoperative complications, especially lower rates of

Table 3 Postoperative outcomes in 110 cases of pancreaticoduodenectomy

\begin{tabular}{|c|c|c|c|c|}
\hline Outcome & All $(n=110)$ & PG group $(n=51)$ & PJ group $(n=59)$ & $P$ value \\
\hline Postoperative complication, n (\%) & $42(38.2)$ & $18(35.3)$ & $24(40.7)$ & 0.562 \\
\hline Mild complications, $n$ (\%) & $7(6.4)$ & $3(5.9)$ & $4(6.8)$ & 0.848 \\
\hline Major complications, n (\%) & $35(31.8)$ & $15(29.4)$ & $20(33.9)$ & 0.614 \\
\hline $\mathrm{CCl}$, mean $\pm \mathrm{SD}$ & $32.7 \pm 2.5$ & $27.0 \pm 2.1$ & $37.0 \pm 3.9$ & 0.045 \\
\hline Pancreatic fistula, $n(\%)$ & $11(10.0)$ & $3(5.9)$ & $8(13.6)$ & 0.181 \\
\hline Pancreatic fistula grade & & & & 0.488 \\
\hline $\mathrm{A}, n(\%)$ & $3(2.7)$ & $1(2.0)$ & $2(3.4)$ & - \\
\hline $\mathrm{B}, n(\%)$ & $6(5.5)$ & $2(3.9)$ & $4(6.8)$ & - \\
\hline $\mathrm{C}, n(\%)$ & $2(1.8)$ & $0(0)$ & $2(3.4)$ & - \\
\hline Biliary fistula, $n$ (\%) & $9(8.2)$ & $2(3.9)$ & $7(11.9)$ & 0.243 \\
\hline Postoperative stay, mean \pm SD & $23.2 \pm 0.9$ & $23.6 \pm 1.6$ & $22.8 \pm 1.0$ & 0.674 \\
\hline Abdominal bleeding, $n$ (\%) & $8(7.3)$ & $4(7.8)$ & $4(6.8)$ & 0.830 \\
\hline Intra-abdominal fluid collection, $n$ (\%) & $14(12.7)$ & $3(5.9)$ & $11(18.6)$ & 0.045 \\
\hline Delayed gastric empting, $n$ (\%) & $11(10.0)$ & $2(3.9)$ & $9(15.3)$ & 0.048 \\
\hline Reoperations, $n(\%)$ & $3(2.7)$ & $1(2.0)$ & $2(3.4)$ & 0.646 \\
\hline
\end{tabular}

$P G$ pancreatogastrostomy, $P J$ pancreatojejunostomy, $\mathrm{CCl}$ comprehensive complication index 
pancreatic leakage. This retrospective study also indicated that PG with mesh-reinforced pancreatoduodenectomy resulted in fewer complications and improved the quality and safety of the pancreatic anastomosis more so than did the PJ with mesh-reinforced following PD.

The reported frequency of pancreatic fistula after pancreaticoduodenectomy varied from 10 to $30 \%$, and pancreatic fistula was considered a serious event that even might be life-threatening in almost half of patients [15, $26,27]$. The reasons for pancreatic fistula were primarily its soft parenchyma, making it more likely to develop parenchymal lacerations from shear forces applied during tying of sutures [17]. In addition, the anastomotic technique, the diameter of pancreatic duct, the general condition of the patients and the various definitions of pancreatic fistula could also affect the incidence of postoperative pancreatic fistula $[14,28-30]$. It was reported that soft pancreatic parenchyma and the diameter of main pancreatic duct less than $3 \mathrm{~mm}$ were risk factors for pancreatic leakage [31, 32]. To prevent these complications, various methods during the preoperative, intraoperative, and postoperative periods have been proposed, especially surgical techniques [33, 34]. For example, it is reported that the application of the novel embeddedness-like pancreaticojejunostomy anastomosis technique in PD was effective and could reduce the incidence of pancreatic fistula [35]. In our hospital, we also introduce a different method of mesh-reinforced technique in PD to reduce postoperative complications.

The rate of pancreatic fistula of $10 \%$ in our study was lower than that of other studies. The technique used in our procedure to reduce morbidity and mortality was modified according to the binding pancreaticojejunostomy described by Peng et al. [16]. There exist some advantages of this technique as previously described [36]. First, the safe anchor site was provided by the mesh for sutures, and this resulted in the ability to avoid leakage and bleeding after surgery for soft and fragile pancreatic tissue. Second, it was more convenient to wrap the pancreatic stump with the bowel loop by changing the shape of the pancreas with mesh reinforcement. In addition, the left edge of the mesh was sutured tightening to the posterior wall of the bowel loop, and it facilitated the pancreas sliding into the bowel loop. Fourth, the likelihood of pancreatic leakage and bleeding was diminished by the mesh compression of pancreatic tissue. Finally, the mesh stimulated the growth of fibroblasts and promoted the healing process between the pancreatic capsule and the bowel mucosa [36-38]. In our study, we proposed various mesh-reinforced surgical techniques to prevent complications, and there were lower rates of several surgical complications.
There are two methods for the restoration of pancreatic drainage into the gastrointestinal tract in $\mathrm{PD}$, including PG and PJ [19, 39, 40]. Not all previous studies yielded similar results. Yeo et al. [41] reported that the rate of pancreatic fistula was almost the same for the PG (12.3\%) and PJ (11.1\%), suggesting that PG was not safer than PJ. However, Bassi et al. [19] found that biliary fistula, postoperative collections and delayed gastric emptying rates were significantly lower in patients with PG than in PJ. Schlitt et al. [20] also suggested that PG was significantly safer than PJ with respect to the incidence of pancreatic fistula. Therefore, there remained a need to compare the two methods following PD. Meshreinforced PG and mesh-reinforced PJ were compared with each other in our study. The mesh-reinforced PG showed advantages in PD in that its comprehensive complication index was lower than that of the mesh-reinforced PJ group. We also showed a significant benefit of mesh-reinforced PG reconstruction compared with mesh-reinforced PJ with respect to intra-abdominal fluid collection and delayed gastric emptying. Pancreatic and biliary fistulas also showed lower trends of incidence in mesh-reinforced PG.

There are additional factors supporting our conclusion that mesh-reinforced PG was superior to PJ. First, the blood supply to the stomach is rich, promoting healing between the stomach and the pancreatic stump [42]. Second, in the acidic gastric environment, pancreatic enzymes will not be activated, preventing deleterious tissue digestion around the anastomosis [43]. Third, a nasogastric tube can be used to decompress, and an endoscope can easily access the anastomosis when needed [43, 44]. However, the learning curve of the surgeon and the experience of the center also influence the method we chose. As a result, we suggest that mesh-reinforced PG can be performed in patients following PD to prevent postoperative complications, especially pancreatic fistulas.

There are several limitations in current study. First of all, as this study was a retrospective observational analysis, it could not exclude the impact of residual confounding factors completely, including the fact that patient distribution between groups depended on surgeon's preference. Second, as it is just a single-center study; multicenter studies are needed for further confirmation. Third, the results lacked a control group without a mesh-reinforced technique; a randomized controlled trial would be necessary to conduct to avoid such bias in the future.

\section{Conclusions}

The current study confirmed that the mesh-reinforced technique may be beneficial in patients following PD. Although mesh-reinforced PG did not show significant 
differences in pancreatic fistulas and biliary fistulas, the CCI, intra-abdominal fluid collection, and delayed gastric emptying were significantly lower in patients with the mesh-reinforced PG than in mesh-reinforced PJ. In summary, the mesh-reinforced technique is preferred during pancreaticoduodenectomy, especially mesh-reinforced pancreatogastrostomy.

\section{Abbreviations}

BMI: Body mass index; CCl: Comprehensive complication index PD: Pancreaticoduodenectomy; PG: Pancreatogastrostomy;

PJ: Pancreatojejunostomy; POPF: Postoperative pancreatic fistula

\section{Acknowledgements}

The authors gratefully acknowledge all of the investigators for their contributions to the trial, as well as Bin Chen, who provided medical writing assistance.

\section{Funding}

This study was funded in part by the Zhejiang Provincial Natural Science Foundation (No. 2017C33159 and No. LY18H030006) and Health and Family Planning Commission of Zhejiang Province Grant (No. 2017ZD019).

\section{Availability of data and materials}

Access to the data and the calculation method can be obtained from the authors by email (gxinjumed09@126.com).

\section{Authors' contributions}

JP and XG contributed to the study conception and design. $X G, W Z, X L$, and JP contributed to the acquisition of the data. $X Z, W Q$, and $L G$ contributed to the analysis and interpretation of the data. JP and $\mathrm{HZ}$ contributed to the drafting of the manuscript. WZ and XW contributed to the critical revision. All authors read and approved the final manuscript.

\section{Ethics approval and consent to participate}

This study was approved by the ethics committee of Sir Run Run Shaw Hospital. Written informed consent was obtained from all participants.

\section{Consent for publication}

Written informed consent was obtained from all patients enrolled in the investigation. The study protocol conformed to the ethical guidelines of the 1975 Declaration of Helsinki and the guidelines of the regional ethical committees of Sir Run Run Shaw Hospital, School of Medicine, Zhejiang University, China.

\section{Competing interests}

The authors declare that they have no competing interests.

\section{Publisher's Note}

Springer Nature remains neutral with regard to jurisdictional claims in published maps and institutional affiliations.

Received: 20 February 2018 Accepted: 5 September 2018

Published online: 17 September 2018

\section{References}

1. Whipple AO, Parsons WB, Mullins CR. Treatment of carcinoma of the ampulla of vater. Ann Surg. 1935;102(4):763-79.

2. Senda Y, Shimizu Y, Natsume S, Ito S, Komori K, Abe T, et al. Randomized clinical trial of duct-to-mucosa versus invagination pancreaticojejunostomy after pancreatoduodenectomy. Br J Surg. 2018;105(1):48-57.

3. Bannone E, Andrianello S, Marchegiani G, Masini G, Malleo G, Bassi C, et al. Postoperative acute pancreatitis following pancreaticoduodenectomy: a determinant of fistula potentially driven by the intraoperative fluid management. Ann Surg. 2018. https://doi.org/10.1097/SLA 0000000000002900 .

4. Wang WG, Babu SR, Wang L, Chen Y, Tian BL, He HB. Use of Clavien-Dindo classification in evaluating complications following pancreaticoduodenectomy in 1,056 cases: a retrospective analysis from one single institution. Oncol Lett. 2018;16(2):2023-9.
5. Kunstman JW, Starker LF, Healy JM, Salem RR. Pancreaticoduodenectomy can be performed safely with rare employment of surgical drains. Am Surg. 2017;83(3):265-73.

6. Hirono S, Kawai M, Okada Kl, Miyazawa M, Kitahata Y, Hayami S, et al. Modified Blumgart mattress suture versus conventional interrupted suture in pancreaticojejunostomy during pancreaticoduodenectomy: randomized controlled trial. Ann Surg. 2018. https://doi.org/10.1097/SLA 0000000000002802

7. De Pastena M, Paiella S, Marchegiani G, Malleo G, Ciprani D, Gasparini C, et al. Postoperative infections represent a major determinant of outcome after pancreaticoduodenectomy: results from a high-volume center. Surgery. 2017;162(4):792-801

8. Lubrano J, Bachelier P, Paye F, Le Treut YP, Chiche L, Sa-Cunha A, et al. Severe postoperative complications decrease overall and disease free survival in pancreatic ductal adenocarcinoma after pancreaticoduodenectomy. Eur J Surg Oncol. 2018;44(7):1078-82.

9. Qiu J, Du C. Pancreatogastrostomy versus pancreatojejunostomy for RECOnstruction after PANCreatoduodenectomy (RECOPANC, DRKS 00000767): perioperative and long-term results of a multicenter randomized controlled trial. Ann Surg. 2017;266(6):e63-e4.

10. D'Souza MA, Shrikhande SV. Pancreatic resectional surgery: an evidencebased perspective. J Cancer Res Ther. 2008;4(2):77-83.

11. Ball CG, Howard TJ. Does the type of pancreaticojejunostomy after Whipple alter the leak rate? Adv Surg. 2010;44:131-48.

12. Kleeff J, Korc M, Apte M, La Vecchia C, Johnson CD, Biankin AV, et al. Pancreatic cancer. Nat Rev Dis Primers. 2016;2:16022.

13. Buchler MW, Friess H, Wagner M, Kulli C, Wagener V, Z'graggen K. Pancreatic fistula after pancreatic head resection. Brit J Surg. 2000;87(7):883-9.

14. Bassi C, Dervenis C, Butturini G, Fingerhut A, Yeo C, Izbicki J, et al. Postoperative pancreatic fistula: an international study group (ISGPF) definition. Surgery. 2005;138(1):8-13.

15. Trede M, Schwall G. The complications of pancreatectomy. Ann Surg. 1988: 207(1):39-47.

16. Peng SY, Mou YP, Liu YB, Su Y, Peng CH, Cai XJ, et al. Binding pancreaticojejunostomy: 150 consecutive cases without leakage. J Gastrointest Surg. 2003;7(7):898-900.

17. Wang XF, Zhou W, Xin Y, Huang DY, Mou YP, Cai XH. A new technique of polypropylene mesh-reinforced pancreaticojejunostomy. Am J Surg. 2007; 194(3):413-5.

18. Zhu YP, Zhou W, Zhang NY, Pan JH, Li B, Wang XF. A new technique of mesh-reinforced pancreaticogastrostomy: report of 13 initial cases. $J$ Laparoendosc Adv S. 2013;23(7):617-20.

19. Bassi C, Falconi M, Molinari E, Salvia R, Butturini G, Sartori N, et al. Reconstruction by pancreaticojejunostomy versus pancreaticogastrostomy following pancreatectomy: results of a comparative study. Ann Surg. 2005 242(6):767-71 discussion 71-3.

20. Schlitt HJ, Schmidt U, Simunec D, Jager M, Aselmann H, Neipp M, et al. Morbidity and mortality associated with pancreatogastrostomy and pancreatojejunostomy following partial pancreatoduodenectomy. Br J Surg. 2002;89(10):1245-51

21. Slankamenac K, Nederlof N, Pessaux $P$, de Jonge J, Wijnhoven BPL, Breitenstein $S$, et al. The comprehensive complication index a novel and more sensitive endpoint for assessing outcome and reducing sample size in randomized controlled trials. Ann Surg. 2014;260(5): 757-63.

22. Dindo D, Demartines N, Clavien PA. Classification of surgical complications - a new proposal with evaluation in a cohort of 6336 patients and results of a survey. Ann Surg. 2004;240(2):205-13.

23. Slankamenac K, Graf R, Barkun J, Puhan MA, Clavien PA. The comprehensive complication index a novel continuous scale to measure surgical morbidity. Ann Surg. 2013;258(1):1-7.

24. Ge X, Dai X, Ding C, Tian H, Yang J, Gong J, et al. Early postoperative decrease of serum albumin predicts surgical outcome in patients undergoing colorectal resection. Dis Colon Rectum. 2017:60(3):326-34.

25. Shen YF, Jin WY. Reconstruction by pancreaticogastrostomy versus pancreaticojejunostomy following pancreaticoduodenectomy: a metaanalysis of randomized controlled trials. Gastroent Res Pract 2012. 2012: 627095. https://doi.org/10.1155/2012/627095.

26. Fabre JM, Arnaud JP, Navarro F, Bergamaschi R, Cervi C, Marrel E, et al. Results of pancreatogastrostomy after pancreatoduodenectomy in 160 consecutive patients. Brit J Surg. 1998;85(6):751-4. 
27. vanBergeHenegouwen MI, DeWit LT, VanGulik TM, Obertop H, Gouma DJ. Incidence, risk factors, and treatment of pancreatic leakage after pancreaticoduodenectomy: drainage versus resection of the pancreatic remnant. J Am Coll Surgeons. 1997;185(1):18-24.

28. Poon RTP, Lo SH, Fong D, Fan ST, Wong J. Prevention of pancreatic anastomotic leakage after pancreaticoduodenectomy. Am J Surg. 2002; 183(1):42-52.

29. Yang $Y M$, Tian $X D$, Zhuang $Y$, Wang WM, Wan YL, Huang YT. Risk factors of pancreatic leakage after pancreaticoduodenectomy. World I Gastroentero. 2005;11(16):2456-61.

30. Azumi Y, Isaji S, Kato H, Nobuoka Y, Kuriyama N, Kishiwada M, et al. A standardized technique for safe pancreaticojejunostomy: pair-watch suturing technique. World J Gastrointest Surg. 2010;2(8):260-4.

31. Bartoli FG, Arnone GB, Ravera G, Bachi V. Pancreatic fistula and relative mortality in malignant disease after pancreaticoduodenectomy. Review and statistical meta-analysis regarding 15 years of literature. Anticancer Res. 1991;11(5):1831-48.

32. Muscari F, Suc B, Kirzin S, Hay JM, Fourtanier G, Fingerhut A, et al. Risk factors for mortality and intra-abdominal complications after pancreatoduodenectomy: multivariate analysis in 300 patients. Surgery. 2006;139(5):591-8.

33. Sakorafas GH, Friess H, Balsiger BM, Buchler MW, Sarr MG. Problems of reconstruction during pancreatoduodenectomy. Dig Surg. 2001;18(5):363-9.

34. Alexakis N, Halloran C, Raraty M, Ghaneh P, Sutton R, Neoptolemos JP. Current standards of surgery for pancreatic cancer. Brit J Surg. 2004;91(11): $1410-27$.

35. Xu X, Lv Y, Zhang L, Xin B, Li JA, Wang D, et al. Application of a novel embeddedness-like pancreaticojejunostomy anastomosis technique used in pancreaticoduodenectomy. Oncol Lett. 2018;15(5):8067-71.

36. Zhong X, Wang X, Pan J, Zhu H, Gu L, Shi Z. Mesh-reinforced pancreaticojejunostomy versus conventional pancreaticojejunostomy after pancreaticoduodenectomy: a retrospective study of 126 patients. World J Surg Oncol. 2018;16(1):68.

37. Continenza MA, Vicentini C, Paradiso-Galatioto G, Fileni A, Tchokogoue E. In vitro study of human dermal fibroblasts seeded on two kinds of surgical meshes: monofilamented polypropylene and multifilamented polyestere. Ital J Anat Embryol. 2003;108(4):231-9.

38. Di Vita G, Patti R, D'Agostino P, Ferlazzo V, Angileri M, Sieli G, et al. Modifications in the production of cytokines and growth factors in drainage fluids following mesh implantation after incisional hernia repair. Am J Surg. 2006;191(6):785-90.

39. Marcus SG, Cohen H, Ranson JH. Optimal management of the pancreatic remnant after pancreaticoduodenectomy. Ann Surg. 1995;221(6):635-45 discussion 45-8.

40. Berger AC, Howard TJ, Kennedy EP, Sauter PK, Bower-Cherry M, Dutkevitch $S$, et al. Does type of pancreaticojejunostomy after pancreaticoduodenectomy decrease rate of pancreatic fistula? A randomized, prospective, dual-institution trial. J Am Coll Surg. 2009;208(5): 738-47 discussion 47-9.

41. Yeo CJ, Cameron JL, Maher MM, Sauter PK, Zahurak ML, Talamini MA, et al. A prospective randomized trial of pancreaticogastrostomy versus pancreaticojejunostomy after pancreaticoduodenectomy. Ann Surg. 1995; 222(4):580-8 discussion 8-92

42. Sauvanet A, Belghiti J, Panis Y, Gayet B, Camara E, Urrejola G, et al. Pancreaticogastrostomy after pancreatoduodenectomy. HPB Surg. 1992;6(2): 91-5 discussion 5-8.

43. McKay A, Mackenzie S, Sutherland FR, Bathe OF, Doig C, Dort J, et al. Metaanalysis of pancreaticojejunostomy versus pancreaticogastrostomy reconstruction after pancreaticoduodenectomy. Br J Surg. 2006:93(8):929-36.

44. Ricci C, Casadei R, Taffurelli G, Pacilio CA, Beltrami D, Minni F. Is pancreaticogastrostomy safer than pancreaticojejunostomy after pancreaticoduodenectomy? A meta-regression analysis of randomized clinical trials. Pancreatology. 2017;17(5):805-13.

Ready to submit your research? Choose BMC and benefit from:

- fast, convenient online submission

- thorough peer review by experienced researchers in your field

- rapid publication on acceptance

- support for research data, including large and complex data types

- gold Open Access which fosters wider collaboration and increased citations

- maximum visibility for your research: over $100 \mathrm{M}$ website views per year

At BMC, research is always in progress.

Learn more biomedcentral.com/submissions 